\title{
Legitimación e institucionalización. El poder militar disciplinario en Chile: bandos y decretos ley $(1973-74)^{1}$
}

\section{The military edicts and law decrees on the institutionalization of civil-military dictatorship by general Augusto Pinochet and its policies of violence (1973-1974)}

\author{
Danny Gonzalo Monsálvez Araneda²
}

\section{Resumen}

A través del Decreto Ley número 5 del 12 de septiembre de 1973 los militares chilenos especificaron que el «Estado de Sitio decretado por conmoción interna» debía entenderse como «Estado o Tiempo de Guerra». De esa forma, y una vez consolidado el golpe de Estado del martes 11 de septiembre, la Junta Militar y las Fuerzas Armadas emprendieron un proceso institucional tendiente a legitimar la acción militar, el combate al marxismo y la eliminación del «enemigo interno», usando para ello todos los instrumentos y mecanismo a disposición con el fin de combatir su presencia en el país. Se adaptó y adoptó una determinada legalidad $\mathrm{y}$, sobre todo, una nueva institucionalidad para esa lucha total y permanente contra el marxismo y sus partidarios. Fue en este contexto de violencia política e institucional en que operaron los Bandos Militares y los Decretos Ley como dispositivos, es decir,

\begin{abstract}
Through Decree Law number 5 of September 12, 1973, the Chilean military specified that the «State of Siege decreed by internal commotion» should be understood as «State or Time of War». In this way, and once the coup d'état of Tuesday September 11 was consolidated, the Military Junta and the Armed Forces undertook an institutional process aimed at legitimizing military action, fighting Marxism and eliminating the «internal enemy», using for this, all the instruments and mechanisms available to combat its presence in the country. A certain legality was adapted and adopted and, above all, a new institutional framework for this total and permanent struggle against Marxism and its supporters. It was in this context of political and institutional violence that the Military Bands and the Decree Law operated as devices, that is, a network of power relations that were structuring a legal
\end{abstract}

${ }^{1}$ Trabajo recibido el 01/04/2020. Aceptado el 30/07/2020.

${ }^{2}$ Universidad de Concepción (Chile). Contacto: monsalvez@gmail.com 
una red de relaciones de poder que fueron estructurando un entramado legal y punitivo tendiente a justificar la represión y eliminación de los opositores al régimen.

Palabras clave: Chile; golpe de Estado 1973; dictadura cívico-militar; violencia política; represión and punitive framework aimed at justifying the repression and elimination of opponents of the regime.

Keywords: Chile; 1973 coup; civil-military dictatorship; political violence; repression

\section{Introducción}

Durante los últimos años, se ha dado un incremento significativo en la producción académica respecto al proceso represivo impulsado por la dictadura chilena encabezada por el general Augusto Pinochet. De esta forma, la sistemática violación de los derechos humanos se ha constituido en uno de los temas más estudiados por parte de las ciencias sociales y las humanidades, particularmente desde el periodismo y la historia. ${ }^{3}$ En todas aquellas investigaciones ha quedado establecido el modo de operar que tuvo la Junta Militar, sus formas, mecanismos y dispositivos institucionales para detener, torturar, asesinar y desaparecer a miles de personas. Si bien quedó bastante documentado, por ejemplo, a través del Informe de la Comisión Nacional de Verdad y Reconciliación (1991) y del Informe de la Comisión Nacional sobre Prisión Política y Tortura (2004), es posible plantearse algunas cuestiones que son importantes a la hora de seguir avanzando en la investigación de estos temas. Por ejemplo, ¿desde dónde emanaban estas órdenes?, ¿̇uál fue el espacio institucional desde donde se pensó y urdió el aparato represivo y de exterminio?, ¿̇cuáles fueron los dispositivos de la violencia política e institucional que urdió la dictadura chilena para justificar y legitimar la represión a nivel interno y externo? Es importante hacer presente estas y otras preguntas cuando nos adentramos en los aspectos más sinuosos y violentos que tuvo el régimen de Pinochet y en cómo comprender los niveles de violencia política institucional a los cuales se pudo llegar durante 17 años de dictadura en Chile.

$\mathrm{Al}$ respecto, es necesario señalar que la institucionalización de la violencia política por parte de la dictadura de Pinochet, es decir, la creación e implementación de una determinada legalidad con el objetivo de

\footnotetext{
${ }^{3}$ Entre otros véase: Salazar (2011 y 2012); Salazar, Ramírez y Hertz (2016); Peñaloza (2015); Dorat y Weibel (2012); Garcés (2005); Escalante, Guzmán, Rebolledo y Vega (2013); Rebolledo (2012).
} 
detener, torturar y hacer desaparecer a miles de ciudadanos, se desarrolló en sus inicios a través de dos mecanismos: en primer término los bandos militares y en segundo lugar los decretos leyes, a lo cual podemos agregar las Actas de la Honorable Junta de Gobierno, siendo éste el espacio institucional y orgánico desde donde se estructuraron las medidas disciplinarias y punitivas.

En vista de aquello, en el siguiente trabajo nos interesa dar una mirada general y de conjunto a estas modalidades y diseños que adquirió la violencia política institucional en los inicios de la dictadura chilena; es decir, dar cuenta de algunos dispositivos legales y jurídicos a través de los cuales se expresó la violencia política e institucional los días y meses posteriores al 11 de septiembre de 1973, particularmente durante el primer año. Si bien este tipo de medidas se enmarcan en un aspecto legal y jurídico, no es menor la lectura política, ideológica y hasta simbólica que se debe hacer de ellos. Detrás de estas medidas institucionales deben observarse aquellas relaciones de poder, en este caso un poder militar y disciplinario que buscó no sólo legitimarse discursivamente, sino que por sobre todas las cosas legal y violentamente.

Las fuentes y archivos que nutren el presente artículo corresponden a la revisión de los bandos militares, los cuales fueron operativos en los inicios de la dictadura, así como también los decretos ley que constituyeron por una parte la continuidad de los bandos y por otra una mayor amplitud y profundización de estos. Lo anterior se complementa con información de prensa y revistas de la época.

Cabe señalar que la violencia política en la historiografía nacional, no es un tema que se ha abordado con suficiente amplitud y profundidad en la disciplina histórica (Monsálvez y Aravena, 2018, pp. 83-99); más bien las indagaciones y la producción sobre aquel tema son acotadas, por lo tanto, la lectura y análisis que podemos hacer de estos dispositivos de la violencia política institucional de la dictadura, nos permiten comprender de mejor forma hasta qué punto la represión hacia un importante sector de la población chilena -particularmente de aquellos que fueron calificados como «enemigos internos» o «antipatriotas»- no constituyó un proceso aislado, casual o espontáneo, más bien formó parte de todo un entramado institucional proveniente desde propio Estado, que con los años se convirtió en una práctica sistémica y permanente bajo la dictadura chilena.

Desde el punto de vista conceptual, la violencia política no tiene una sola lectura o interpretación (Aróstegui, 1996; Turk, 1996; Cortina, 
1996; González Calleja, 2002), pero existe cierto consenso en señalar que se trata de un tipo particular de violencia que se da de forma vertical entre gobernantes y gobernados y donde los primeros dominan los procesos de legalización y criminalización. Se impone una determinada legalidad que tiene como objetivo la coerción psicológica y física de aquellos grupos o sectores que desafían determinadas normas legales. A partir de aquello, los grupos dominantes no sólo utilizan la ley para penalizar determinados actos o acciones, sino también para ampliar y consolidar la dominación. En todo este proceso, la violencia política adquiere determinadas formas y dinámicas, por ejemplo la irrupción de una violencia coercitiva, para persuadir a los adversarios o enemigos; la violencia lesiva, que busca castigar conductas; y, finalmente, una violencia destructiva, que tiene como objetivo la exterminación del otro (Turk, 1996, p. 48).

\section{Los bandos militares}

Según Manuel Antonio Garretón, Roberto Garretón y Carmen Garretón (1998), los bandos militares cumplieron en los primeros meses de la dictadura una triple función «ideológico-programática, normativo-institucional e informativo-propagandística» (p. 14) Así, a contar del martes 11 de septiembre de 1973, los bandos militares pasaron a constituirse en el fundamento ideológico e institucional que sirvió de marco legitimatorio y guía, tanto para los militares como para los civiles que respaldaban las acciones llevadas adelante por las Fuerzas Armadas y Carabineros; además de convertirse en un mecanismo de indagación para una sociedad fuertemente militarizada.

Si bien los bandos tuvieron corta duración, su importancia no radica tanto en aquel punto, sino en su efectividad, ya sea en cuanto mensaje a la población o por las medidas que estos contemplaban. En aquel mes de septiembre de 1973, los bandos, que desde el punto de vista factual se desplegaron entre el 11 y 21, pasaron a delimitar el campo de lo permitido y prohibido, así como lo legítimo e ilegitimo no sólo en el ámbito político, social, también valórico y cultural. En consecuencia, los bandos militares se constituyeron en la práctica en la expresión de la voluntad inmediata del poder y se podían aplicar en tanto éste lo dispusiera. Había allí una relación de forma y fondo: se definía una situación, se decía qué había que hacer, pero sobre todo se decía que había alguien que 
tendría la atribución de juzgar y evaluar esa conducta. Junto a la materialidad de la orden y la norma, estaba el símbolo de la sociedad como cuartel o en estado de guerra, donde al que mandaba todo lo estaba permitido (Garretón, 1998, pp. 18-19).

De esta manera, se hace necesario tener presente dos aspectos del bando, entendido como dispositivo de control social. Por un lado, se buscaba crear un clima emocional psico-social que hiciera más vulnerable y manipulable a la población. Por el otro lado, la función informativa era siempre propagandística, es decir, no pretendía dar cuenta de una realidad sino interpretarla. Por eso los bandos entregaban ciertas informaciones, pero ocultaban otras, ya sea tergiversándolas, ya sea negándolas (Garretón, 1998, pp. 18-19).

Desde el punto de vista de la definición o caracterización, un bando resulta difícil de conceptualizar ya que jurídicamente tiene «escaso desarrollo en la legislación chilena». Hacia el 11 de septiembre de 1973, los bandos «sólo aparecen mencionados en el Código de Justicia Militar y en la Ley de Seguridad Interior del Estado»; ahora, para el caso del presente trabajo, el bando tiene un carácter de «notificación, escrita u oral, de un mandato y no era el mandato mismo», por lo tanto «tiene un carácter esencialmente público, lo que nos lleva ya a una primera comprobación en el caso que nos ocupa: los bandos dictados por la Junta Militar y los Jefes de Zona de la dictadura que se instauraron el 11 de septiembre de 1973 nunca fueron solemnemente publicados. Incluso hoy cuesta conseguirlos» (Garreton, 1998, pp. 21-22) Es decir, los bandos militares, si bien fueron publicados o reproducidos en determinados medios de prensa, por ejemplo diario El Mercurio, tuvieron en su esencia el carácter de secretos, lo cual se enmarca en la política militar o de guerra interna que la Junta Militar chilena estableció en los inicios del régimen. En otras palabras, la característica secreta de los bandos forma parte de un entramado mayor, en el cual se enmarcan por ejemplo cárceles secretas, leyes secretas, actas y sesiones secretas, policías secretas, agentes secretos y entierros secretos, entre otros aspectos (Salazar, 2011 y Rebolledo, 2012).

En palabras de Robert Barros (2005), en medio de la falta de organización militar y legal, las Fuerzas Armadas emitieron bandos para dar instrucciones a la población civil. Dichos bandos eran edictos penales $\mathrm{y}$ administrativos excepcionales sin fundamento constitucional y, según el Código de Justicia Militar, podían ser utilizados en tiempos de guerra para gobernar a las tropas y a los habitantes de los territorios ocupados. 
Será precisamente, estos ejemplos, los que nos permitan caracterizar los bandos más allá de una lectura jurídica y como a través de éstos, se buscó reglamentar ciertas áreas del quehacer nacional. $\mathrm{Al}$ respecto y desde un punto de vista metodológico, podemos dividir los bandos en ciertas categorías para una mejor comprensión.

\section{Tenor del mensaje y discursos a la población en los bandos}

Algunos bandos tuvieron como objetivo informar a la población sobre las medidas que se estaban ejecutando. Cumplieron la función de ser discursos que intentaron persuadir a los ciudadanos con el objetivo de consensuar apoyo sobre las acciones emprendidas por las Fuerzas Armadas y Carabineros. Dichos bandos contienen un fuerte componente moralista, de redención patriótica, apelando a determinados valores como el orden, disciplina, respeto y jerarquía, todos ellos, alterados o transgredidos, según la Junta Militar, por el marxismo y sus partidarios.

Por ejemplo, dentro de esta categoría podemos mencionar los bandos número 4, 5 y 6 . El primero de ellos estaba dirigido a los jóvenes del país, quienes «...deben confiar en los destinos superiores de Chile y en las FF. AA., que serán las encargadas de velar por ellos», por lo tanto, deben obedecer a los bandos y las instrucciones que emanen de ellos. En el mismo bando se hace referencia a los padres como los encargados y responsables de mantener la calma de los espíritus al interior de la familia, con el objetivo de «restablecer el núcleo familiar», por lo tanto, «deben cooperar al mantenimiento del orden, cuidando que sus hijos no abandonen el hogar, hasta que aquel sea íntegramente establecido». ${ }^{4}$

Por su parte, el bando número 5 contiene una larga explicación y fundamentación de las razones por las cuales las Fuerzas Armadas decidieron poner fin al gobierno de la Unidad Popular. Entre otros aspectos, apuntaban que el gobierno de Salvador Allende había incurrido reiteradamente en una ilegitimidad «al quebrantar los derechos fundamentales de libertad de expresión, libertad de enseñanza, derecho de huelga, derechos de petición, derecho de propiedad, y derecho en general, a una digna y segura subsistencia». ${ }^{5}$ Además de aquello, habría quebrantado la unidad nacional, «fomentando artificialmente una lucha de clases estéril

\footnotetext{
${ }^{4}$ El Mercurio, 26/09/1973, p. 23.

${ }^{5}$ El Mercurio, 26/09/1973, p. 23.
} 
y en muchos casos cruenta», dañando con aquello el bien de la Patria. De acuerdo con estos argumentos, el no cumplimiento y respeto a las decisiones del Congreso, Poder Judicial y Contraloría, había sumido al país en una «...anarquía, asfixia de libertades, desquiciamiento moral y económico». Todo aquello había puesto en peligro la «seguridad interna y externa del país»; por lo tanto, eran elementos más que suficientes para «...justificar nuestra intervención para deponer al gobierno ilegítimo, inmoral y no representativo del gran sentir nacional». En consecuencia, las Fuerzas Armadas:

han asumido el deber moral que la Patria les impone de destituir al Gobierno que aunque inicialmente legítimo ha caído en la ilegitimidad flagrante, asumiendo el Poder por el sólo lapso en que las circunstancias lo exijan, apoyado en la evidencia del sentir de la gran mayoría nacional, la cual de por sí, ante Dios y ante la Historia, hace justo su actuar y por ende, las resoluciones, normas e instrucciones que se dicten para la consecución de la tarea de bien común y de alto interés patriótico que se dispone cumplir. ${ }^{6}$

Finalmente en el bando número 6, se reiteró el objetivo primordial de la Junta Militar: «...luchar hasta las últimas consecuencias para derrocar al gobierno marxista». ${ }^{7}$

Otros bandos, como el número 14, tuvieron como objetivo entregar un mensaje a la población, los trabajadores y medios de comunicación; mientras que el bando número 20 apuntó a los extranjeros que se encontraban en el país, en el sentido que estos debían mantener la calma. En el caso de estos últimos, aquellos que estuvieran en situación irregular o ilegal «...deberán presentarse de inmediato en las Comandancias más cercanas o a la Patrulla Militar más próxima». ${ }^{8}$

El bando que mejor ilustró el carácter de mensaje informativo a la población fue el número 26, que en el punto 1 señalaba lo siguiente: «Para conocimiento de la ciudadanía se expone una breve síntesis de las principales actividades desarrolladas por las Fuerzas Armadas y Carabineros hasta las 16.00 horas de hoy 12 de septiembre de 1973, en la guarnición de Santiago». ${ }^{9}$ En dicho bando se daba cuenta de las acciones

\footnotetext{
${ }^{6}$ El Mercurio, 26/09/1973, p. 23.

${ }^{7}$ El Mercurio, 26/09/1973, p. 23.

${ }^{8}$ El Mercurio, 26/09/1973, p. 23.

${ }^{9}$ El Mercurio, 26/09/1973, p. 23.
} 
emprendidas por la autoridad militar a manera de resumen. Al respecto podemos citar las siguientes acciones: ocupación del Palacio de Gobierno y la Residencia Presidencial de Tomas Moro, en la cual se «...incautó una gran cantidad de armas y explosivos»; ocupación y allanamiento de industrias (Hirmas, ex Yarur, Sumar), Banco del Estado, Banco de Chile, Diario La Nación, en estas últimas, también se encontraron armas; ocupación del Ministerio de Obras Públicas y la reducción de «extremistas armados» y ocupación del Diario Clarín y Revista Punto Final; «ocupación y allanamiento de la Universidad Técnica del Estado después de resistencia armada con rendición de aproximadamente 600 personas e indicación de gran cantidad de armamento y extranjeros». ${ }^{10}$

En el caso de los extranjeros presentes en Chile, se informa de la «Rendición de 150 cubanos extremistas e incautación de gran cantidad de armamentos. Estos harán abandono esta tarde de nuestra patria». Finalmente, la Junta Militar, agradeció a la ciudadanía,

la cual en cumplimiento a la centenaria tradición democrática y patriótica en defensa de los altos intereses de la Patria, ha permitido con su oportuna información controlar y destruir estos importantes núcleos extremistas y tener actualizado el cuadro de los extremistas y extranjeros subversivos residentes, para limpiar nuestra Patria de elementos indeseables que nada tiene que ver con nuestra tierra y origen común. ${ }^{11}$

Las mismas expresiones se repitieron siete días más tarde en el bando número 35, oportunidad en la cual la Junta Militar manifestó «su profundo reconocimiento a la ciudadanía por el gran espíritu de responsabilidad demostrado al denunciar a los extremistas que en forma suicida estuvieron operando en algunos sectores de la capital». ${ }^{12}$

\section{Tenor de los mensajes y medidas punitivas en los bandos}

En esta categoría se encuentran aquellos bandos que tuvieron como objetivo, por una parte, dar cuenta e informar sobre la situación que se estaba viviendo en el país, además de mantener al tanto a la población de

\footnotetext{
${ }^{10}$ El Mercurio, 26/09/1973, p. 23.

${ }^{11}$ El Mercurio, 26/09/1973, p. 23.

${ }^{12}$ El Mercurio, 26/09/1973, p. 23.
} 
las medidas que se estaban llevando a cabo, y por otro lado informar de las medidas y disposiciones de carácter punitivo y sancionatorias que se impulsaron de acuerdo a la situación interna del país (tiempo de guerra). En el caso de estos bandos, y a diferencia de los anteriores, no solamente se enviaba un mensaje de carácter informativo a la población, también iba acompañado de algunas medidas concretas que se implementarían en caso de no darse cumplimiento al bando o se produjera una desobediencia por parte de la población a las ordenes emanadas de esta.

En este marco operó el bando número 3 que hizo un llamado a la población a no «dejarse llevar por las incitaciones a la violencia que puedan emanar de activistas nacionales o extranjeros», en caso contrario «serán sometidos al rigor de la Justicia Militar». ${ }^{13}$ Por otra parte, los bandos 9 al 12 realizaron un llamado a determinados sectores de la población a obedecer las instrucciones que entregase la autoridad castrense. Así por ejemplo, el bando 9

advierte a los profesionales, empleados y obreros de las empresas ocupadas, que deben tener absoluta calma y abstenerse de efectuar provocaciones al personal de las FF. AA. y de Orden. Cualquier acción en tal sentido, así como acciones de sabotaje, violencia física contra civiles o intentos de resistencia, serán reprimidos sin contemplaciones en acciones militares de tierra y aire similares a las efectuadas en contra de La Moneda y de la Residencia Presidencial de Tomás Moro. ${ }^{14}$

Mientras que el bando número 10, de manera directa y explícita hizo un llamado a modo de ultimátum dirigido a los dirigentes del otrora gobierno de la Unidad Popular para que se presentaran antes de las 16.30 horas en el Ministerio de Defensa Nacional. La no concurrencia implicaba «...ponerse al margen de los dispuesto por la Junta de Comandantes en Jefe con las consecuencias fáciles de prever». ${ }^{15}$

Por otro lado, en el bando número 12 se advirtió a los medios de comunicación (prensa, radio y canales de televisión) que cualquier información que se diera a conocer y no estuviera «confirmada por la Junta de Gobierno Militar» significaría la intervención inmediata de dicho medio

\footnotetext{
${ }^{13}$ El Mercurio, 26/09/1973, p. 23.

${ }^{14}$ El Mercurio, 26/09/1973, p. 23.

${ }^{15}$ El Mercurio, 26/09/1973, p. 23.
} 
a través de las Fuerzas Armadas, «sin perjuicio de la responsabilidad penal que la junta determine en su oportunidad». ${ }^{16}$ Como una forma de complementar lo señalado en el bando anterior, la Junta Militar estableció una «estricta Censura de Prensa», cuyo objetivo fue mantener -en palabras de la autoridad militar- correctamente informada a la población. Es por ello que como «medida precautoria» para el día 12 de septiembre solamente se autorizó la circulación de dos diarios: El Mercurio y La Tercera de la Hora. Asimismo, y para resguardar el debido cumplimiento de dicho dictamen, «Se ha designado una Oficina de Censura de Prensa, que funcionará en la Academia Politécnica Militar del Ejército (San Ignacio $\mathrm{N}^{\circ} 242$ ), que tendrá bajo su control las publicaciones escritas autorizadas; el sistema a emplear será el de CENSURA a la edición impresa». Esto significó en la práctica, que las ediciones de los diarios $E l$ Mercurio y La Tercera debieron ser entregadas diariamente a este organismo para su respectiva «evaluación» y autorización antes de ser publicadas. En caso que alguna otra publicación no fuera autorizada por la Junta Militar «será requisada y destruida». El objetivo de estas medidas -en palabras de las autoridades militares- era «depurar las publicaciones de prensa, en orden a no aceptar en lo sucesivo insultos a personas ni instituciones, como asimismo el lenguaje procaz, por lo que se estima de inmediata solución restablecer la convivencia nacional y normas éticas». ${ }^{17}$

En relación a las informaciones proporcionadas por miembros de las Fuerzas Armadas sobre la cantidad de armamento encontrado en diversos lugares, la Junta emitió algunos bandos, como el número 17, 22 y 24 , en los cuales se invitaba a la población a la entrega de «cualquier tipo de arma o explosivo no registrado» en un plazo no superior al 13 de septiembre de 1973. Aquellas personas que no dieran cumplimiento a esta medida «será[n] castigada[s] con todo el rigor de la Ley Militar y de Control de Armas». El mismo llamado se realizó con aquellas personas o «elementos subversivos que pretenden resistir la decisión patriótica adoptada por las FF. AA. y de Orden». ${ }^{18}$

\footnotetext{
${ }^{16}$ El Mercurio, 26/09/1973, p. 23.

${ }^{17}$ El Mercurio, 26/09/1973, p. 23.

${ }_{18}$ El Mercurio, 26/09/1973, p. 23.
} 


\section{Tenor punitivo de los bandos}

Ciertos bandos tuvieron como objetivo dar cuenta de las medidas penales y disciplinarias que se aplicaron en el acto contra todas aquellas personas, medios, instituciones u organizaciones que vulneraron o no acataron las disposiciones emanadas de la Junta Militar.

El bando número 8 dejó constancia de aquello, al señalar que la «Residencia Presidencial de Tomás Moro tuvo que ser bombardeada por ofrecer resistencia con personal del GAP a las Fuerzas Armadas y de Carabineros»; del mismo modo, quedó prohibida la presencia de grupos de personas en las calles. Para «reglamentar» dicha determinación, a través del bando número 16 se ordenó el «Toque de Queda» en todo el territorio entre las 18.00 y las 06.30 horas. Durante estas horas no podrían transitar personas, grupos, vehículos o cualquier otro medio por la vía pública. Por lo tanto, las personas debían permanecer en sus hogares o lugares de trabajo. Solamente se entregaron salvoconductos individuales para aquellos ciudadanos «que deban atender los servicios esenciales, sin excepción de ninguna especie» o bien para personas y vehículos previo estudio de los motivos esgrimidos. Se argumentó que el objetivo de esta medida, que al parecer de las propias autoridades estaba claro que generaría algunos inconvenientes a la ciudadanía, era proteger la seguridad y la vida de las personas y seres inocentes «ante la acción de algunos grupos extremistas». ${ }^{19}$ Como forma de resguardar el orden y la disciplina en el espacio público se dispuso, por medio del bando 32, que toda aquella persona que durante el «Estado de Sitio» fuera sorprendida imprimiendo o difundiendo «por cualquier medio propaganda subversiva y atentatoria contra el Supremo Gobierno sufrirá las penas contempladas por el Código de Justicia Militar para tiempo de Guerra». ${ }^{20}$

Una de las medidas disciplinarias relacionadas con el ámbito político fue la clausura del Congreso Nacional. La Junta Militar decidió el cierre de este espacio de deliberación y consenso entre partidos como una forma de sancionar la actividad política hasta ese entonces desarrollada en Chile, que en opinión de los militares había dañado la convivencia nacional, generando divisiones y odios; por lo tanto, declaró vacantes «los cargos de los Parlamentarios que actualmente invisten tal calidad». Además, al cesar en sus funciones al Congreso y a los parlamentarios, la

\footnotetext{
${ }^{19}$ El Mercurio, 26/09/1973, p. 23.

${ }^{20}$ El Mercurio, 26/09/1973, p. 23.
} 
Junta asumió la responsabilidad de legislar de acuerdo a la nueva realidad nacional impuesta por ellos mismos.

En consecuencia, producido el golpe de Estado, la Junta Militar de gobierno convirtió los bandos militares en su principal manifestación ideológica, su única fuente normativa de institucionalidad y el principal medio de comunicación «...entre los que se toman el poder político, los militares y civiles que les siguen y el conjunto de la sociedad». En la práctica y en concreto, por medio de los bandos la Junta de Comandantes en Jefe de las Fuerzas Armadas, imaginó y proyectó el país como un «inmenso cuartel o campo de concentración», el cual necesitaba ser custodiado, regido y tutelado con mano militar, y aquello pasaba necesariamente por tomar medidas administrativas, punitivas y sancionatorias contra todos aquellos que se situaran fuera o en contra de aquel «cuartel o campo de concentración» (Garretón, 1998, p. 51).

\section{Los decretos ley}

Robert Barros (2005) señala que al momento del golpe de Estado «...las Fuerzas Armadas llegaron al poder en septiembre de 1973 con una concepción rudimentaria, en el mejor de los casos, de cómo estructurar un gobierno militar» (p. 65). En medio de estas incertidumbres, eran más interrogantes que certezas los que por aquellas horas circulaban entre los militares y sus asesores civiles. Si bien los bandos militares cumplieron la función de dar instrucciones a la población, fue necesario recurrir a otro dispositivo que diera mayor sustento y proyección a las medidas que se comenzaban a establecer una vez que iba quedando atrás la acción militar del día martes 11 de septiembre.

Fue en ese contexto cuando entraron en escena los Decretos Ley que tal como señala el Informe de la Comisión Nacional sobre Prisión Política y Tortura (2004) se enmarcaron en un momento y unas necesidades muy concretas. «La Junta Militar procedió a fijar sus propias atribuciones y a subordinar el ejercicio de otros poderes del Estado a las necesidades del momento», fue así como desplegó una intensa actividad legislativa a través de los Decretos Ley (Comisión Nacional sobre Prisión Política y Tortura, 2004, p. 170). Es decir, estos decretos sustituyeron en la práctica el ejercicio legislativo que hasta el 11 de septiembre del 73 cumplía el Congreso Nacional. 
El citado Barros agrega que el primer Decreto Ley fue redactado por Sergio Rillón Romani, asesor legal naval. ${ }^{21}$ Dicho decreto «tenía por modelo el documento fundamente de la junta chilena anterior, la República Socialista de 1932, afirmación confirmada por la considerable similitud entre el primer decreto ley de 1973 y los dos primeros decretos de la junta de 1932». Lo cierto es que más allá de lo breve y puntual del decreto, éste se convirtió en «el primer instrumento para darle un marco legal a la Junta» (Barros, 2005, p. 69).

A medida que trascurrieron las horas y los días, la Junta Militar se encaminó progresivamente en la política de ir centralizando y coordinando las facultades para crear leyes y administrarlas; es decir, dar forma legal a la política de acuerdo a los intereses del nuevo régimen. Fue así como entre otras cosas se creó el Comité de Asesoría y Coordinación Jurídica de la Junta de Gobierno y -prácticamente a unos días del golpese nombró una comisión de prominentes profesores de derecho constitucional y ex políticos, la Comisión Constituyente, con el fin de comenzar a elaborar el borrador de una nueva Constitución (Barros, 2005, p. $70)$.

Es aquí donde se produjo una directa relación entre los bandos y decretos leyes; en otras palabras, y como ya se ha señalado, los segundos constituyeron un complemento y ampliación de los primeros. Desde el punto de vista de nuestro estudio, tanto los bandos como los decretos ley forman parte del proceso que conocemos como la institucionalización de la violencia política. Estos dispositivos legales y punitivos fueron creados para vigilar, castigar y disciplinar a la población; es decir, la Junta Militar instituyó por medio de los bandos y decretos una determinada legalidad, todo un entramado punitivo para legitimar su accionar contra los denominados «enemigos internos». Parafraseando a Austin Turk (1996) y su definición de violencia política, tras el golpe de Estado los militares pasaron a dominar los procesos de legalización y criminalización, lo cual significó establecer leyes que fueron obligatorias para toda la población, y al mismo tiempo impusieron una legalidad que tuvo por objeto la dominación psicológica y física de aquellas personas, grupos o sectores que desafiaron las normas establecidas por el poder militar (pp. 42-43). De

${ }^{21}$ De acuerdo al Acta Secreta número 6, del 20 de septiembre de 1973, la Junta de Gobierno acuerda «designar Subsecretario de Gobierno al Capitán de Navío de Justicia al Sr. SERGIO RILLON R.». 
esta forma, la Junta Militar utilizó la ley no sólo como un mecanismo de castigo, sino también para ampliar y consolidar su dominación.

Como una manera de ejemplificar lo señalado en líneas anteriores, citemos algunos decretos ley los cuales se enmarcan en aquel proceso de legalización y criminalización al cual nos hemos referido en el párrafo anterior y que tienen como objetivo sancionar determinados actos $\mathrm{y}$ al mismo tiempo ir fortaleciendo el proceso de control militar sobre el territorio nacional.

Como es de público conocimiento, el decreto ley número 1 estableció la constitución de la Junta de Gobierno, asumiendo el «mandato supremo de la Nación, con el patriótico compromiso de restaurar la chilenidad, la justicia y la institucionalidad quebrantada», siendo nombrado Augusto Pinochet como Presidente de la Junta. ${ }^{22}$

A contar del decreto número 3, con la declaración del «Estado de Sitio en todo el territorio de la República», comenzaron a operar las medidas correccionales y disciplinarias. Como una forma de aclarar y complementar lo anterior, el decreto ley número 6 estableció que el país se encontraba en una «situación de conmoción interna», por lo tanto era perentorio «reprimir de la forma más drástica posible las acciones que se están cometiendo contra la integridad física del personal de las Fuerzas Armadas, de Carabineros y de la población en general». A consecuencia de aquello se hizo necesario dotar de mayores atribuciones a los Tribunales Militares en la represión de algunos delitos respecto a la Ley de Control de Armas (número 17.798). Por lo tanto, el «estado de sitio decretado por conmoción interna» se entendió como «estado o tiempo de guerra» de acuerdo al artículo 418 del Código de Justicia Militar. ${ }^{23}$

Esta fue una de las principales disposiciones legales que estableció la Junta Militar. En la práctica significó que la población quedó sujeta a los mandatos jurídicos militares y los respectivos consejos de guerra. De esta forma, las Fuerzas Armadas, representadas por los jefes militares de zona, asumieron el control total del país. Su objetivo fue establecer un «Estado de Seguridad Nacional» sobre la bases de una legislación que fuera funcional y operativa a dicho proyecto. Es aquí donde operó con mayor fuerza la violencia política del régimen, es decir, se fue produciendo la institucionalización de la violencia por medio de la creación de un cierto marco institucional que buscó establecer un orden legal y así san-

\footnotetext{
22 Decreto Ley Número 1, 1973, p. 7.

${ }^{23}$ Decreto Ley Números 3 y 4, 1973, pp. 10, 15 y 16.
} 
cionar actitudes, conductas y comportamientos de vastos sectores de la población o de aquellos espacios institucionales y sociales a través de los cuales estos se representaban. Como primera muestra de aquel poder militar punitivo, se procedió a cancelar la personalidad jurídica del organismo que congregaba a los trabajadores chilenos, la Central Única de Trabajadores,

por haberse transformado en un organismo de carácter político, bajo la influencia de tendencias foráneas y ajenas al sentir nacional, prohibiéndose en consecuencia su existencia y toda organización y acción, propaganda de palabra, por escrito o por cualquier otro medio, que revelen, directa o indirectamente su funcionamiento. ${ }^{24}$

El no cumplimiento de esta norma significaba la pena de «presidio, relegación o extrañamiento mayores en cualquiera de sus grados». ${ }^{25}$

Si bien la Junta Militar expresó que los trabajadores no debían temer a las determinaciones que se estaban impulsando, a comienzos de octubre de 1973 se estableció un «tribunal especial» para el tema de los despidos como una forma de complementar las medidas disciplinarias contra los trabajadores. El objetivo declarado fue «restablecer el principio de la disciplina laboral en las actividades laborales». Ahora, si algún trabajador se sentía vulnerado en sus derechos tenía la opción de concurrir ante un «tribunal especial», el cual funcionó en cada departamento del país. Dicho tribunal estaba compuesto por un Juez del departamento, un representante de las Fuerzas Armadas y Carabineros, el cual será designado por el Intendente o Gobernador respectivo, y por un inspector del trabajo, el cual fue escogido por el Director del Trabajo.

¿Cuáles fueron los motivos para terminar un contrato? El decreto Ley número 32 indicó algunos de ellos: atentados contra bienes situados en la empresa; actos que hubieran destruido o destruyeran materiales, instrumentos o productos del trabajo; interrumpir o paralizar de manera ilegal las actividades de empresas o servicios, así como aquellos actos violentos en la empresa o lugar de trabajo; destruir, interrumpir, dañar instalaciones públicas o privadas y colaborar en la introducción, fabricación o almacenamiento de transporte o armas sin la autorización que corresponde. ${ }^{26}$

\footnotetext{
${ }^{24}$ Decreto Ley número 12, 1973, p. 30.

${ }^{25}$ Decreto Ley número 12, 1973, p. 30.

${ }^{26}$ Decreto Ley Número 32, 1973, pp. 70 a 72.
} 
Pero esto no fue todo. Igualmente se dispuso la destitución de empleados por «ineptitud u otro motivo» que «haga inútil o perjudicial su servicio, en conformidad a las leyes orgánicas de los distintos servicios». Todo aquello quedó en manos del Presidente de la República, de acuerdo al artículo 72, número 8 de la Constitución Política de 1925, especialmente en las «circunstancias especiales que vive el país». ${ }^{27}$ En el mismo ámbito del trabajo se estableció aumentar la jornada laboral: «Auméntase en cuatro (4) horas semanales la jornada ordinaria de trabajo», como una forma de aumentar la producción, lo cual iría en directo beneficio de una más rápida reconstrucción del país (Decreto Ley Número 35,1973 , p. 80) No contentos con aquellas disposiciones, y ante la necesidad de «restablecer los principios del orden, disciplina, jerarquía y moralidad pública», se decidió «reorganizar todos los servicios de la administración pública, organismos e instituciones» del Estado (Decreto Ley Número 98, 1973, p. 245) Con estas medidas los funcionarios públicos quedaron en la absoluta indefensión y a merced de las órdenes o requerimientos de las nuevas autoridades.

Como habíamos señalado en pasajes anteriores, uno de los espacios intervenidos por la Junta fue el Congreso, sus funcionarios fueron designados en comisión de servicios en algunas de las reparticiones del Estado. El argumento para proceder con dicha medida quedó establecido en las letras b y c del decreto ley. Mientras el primero señalaba la necesidad de «contar con la mayor expedición en el cumplimiento de los postulados que la Junta de Gobierno se ha impuesto», el punto c se refirió a la imposibilidad por parte de la Junta de someterse a los requerimientos legislativos ordinarios, ya que eso implicaba demorar y entorpecer la urgencia que requiere poner en marcha el restablecimiento de la institucionalidad quebrantada. Como una forma de evitar aquello se procedió a clausurar el Congreso Nacional, con lo cual la Junta Militar asumió el poder de instituir las leyes y la legislación que, «a juicio de las nuevas autoridades», requería el país para volver a la normalidad y restablecer la institucionalidad quebrantada. ${ }^{28}$

\footnotetext{
${ }^{27}$ Decreto Ley Número 66, 1973, p. 162. Cabe agregar que el Artículo 72, número 8 de la Constitución Política de 1925 señala lo siguiente: «Destituir a los empleados de su designación, por ineptitud u otro motivo que haga inútil o perjudicial su servicio, con acuerdo del Senado, si son jefes de oficinas, o empleados superiores, y con informe de la autoridad respectiva, si son empleados subalternos, en conformidad a las leyes orgánicas de cada servicio».
}

${ }^{28}$ Decreto Ley Número 27, 1973, p. 27. 
Un tercer espacio en que se hizo sentir la injerencia militar fueron las universidades. A ojos de los uniformados, se habían convertido en espacios de proselitismo político al servicio del marxismo y en ellas se estaba desarrollando un proceso de concientización ideológica, con lo cual se alteraba su condición de centros académicos abocados en exclusiva al estudio y formación profesional de los jóvenes. Por lo tanto, como una forma de ordenar y disciplinar el régimen interno universitario la Junta Militar procedió a su reorganización, designando Rectores-Delegados con todas las atribuciones que correspondían a los Rectores de dichas universidades. ${ }^{29}$

Un cuarto campo intervenido fueron los partidos políticos. En primera instancia se consideró asociaciones ilícitas a «los Partidos Comunistas, Socialista, Unión Socialista Popular, Movimiento de Acción Popular Unitaria, Radical, Izquierda Cristiana, Acción Popular Independiente y todas aquellas entidades, agrupaciones, facciones o movimientos que sustenten la doctrina marxista». ${ }^{30}$ A todas estas organizaciones se les canceló la personalidad jurídica y sus bienes pasaron a dominio del Estado, siendo la Junta de Gobierno quien establecería su destino. A menos de una semana de tomar esta medida, la Junta dio un nuevo paso contra las agrupaciones políticas, declarando en receso a «todos los partidos y entidades, agrupaciones, facciones o movimientos de carácter político no comprometidos en el decreto ley $\mathrm{N}^{\circ} 77$, del 8 de octubre de $1973 »{ }^{31}$

En materia de información o publicidad se acordó sancionar todos aquellos «delitos flagrantes de ultraje a las buenas costumbres». Para dichos casos, la fuerza pública procedió a recoger en el acto los «escritos, impresos, carteles, afiches y cualquier otro medio que haya servido para cometer el delito». ${ }^{32}$

En medio de todo este proceso de concentración del poder político, los comandantes en jefes emitieron el decreto ley 128, en el cual dejaron claramente estipulado que a contar del 11 de septiembre de 1973 la Junta había asumido el «ejercicio de los Poderes Constituyente, Legislativo y Ejecutivo», mientras que «El Poder Judicial ejercerá sus funciones en la forma y con la independencia y facultades que señale la Constitución Política del Estado». El poder constituyente y legislativo se ejerce-

\footnotetext{
${ }^{29}$ Decreto Ley Número 50, 1973, p. 109.

${ }^{30}$ Decreto Ley Número 77, 1973, p. 179.

${ }^{31}$ Decreto Ley Número 78, 1973, p. 182.

32 Decreto Ley Número 14, 1973, p. 35.
} 
ría «mediante decretos leyes con la firma de todos sus miembros y, cuando éstos lo estimen conveniente, con la de el o los Ministros respectivos». ${ }^{33}$

El proceso de «regeneración política» no se agotó con el cierre del Congreso Nacional, la proscripción de los partidos políticos, la confiscación de sus bienes y la persecución a los dirigentes y militantes de las agrupaciones políticas y sindicales de izquierda; también se hizo necesario declarar la caducidad de los registros electorales, ya que en opinión de la Junta Militar éstos eran producto de una institucionalidad corrompida, particularmente por parte del gobierno de la Unidad Popular. Como consecuencia de aquello, estaban llenos de vicios y «fraudes electorales», tal como lo había demostrado la última elección parlamentaria de marzo de 1973, cuando un sector de la oposición denunció adulteración de las inscripciones electorales. ${ }^{34}$ Por lo tanto, los registros electorales dejaron de funcionar. No se realizaron inscripciones hasta el estudio de un nuevo sistema que garantizara «seriedad y eficiencia del pronunciamiento ciudadano». ${ }^{35}$

Si la intervención (control) en el ámbito universitario fue uno de los primeros objetivos de la Junta Militar, el ámbito escolar constituyó uno de los lugares donde desplegó su presencia con mayor fuerza. Los militares sabían que si querían impulsar todo un proceso de regeneración y refundación enmarcado en una «cultura política autoritaria» la escuela pasaba a constituirse en un terreno privilegiado para llevarlo a cabo. Como una forma de «institucionalizar» una nueva historia e instituir una cierta «liturgia patriótica»y ante «la situación de anarquía en que se desenvuelve la Enseñanza Normal, tanto en sus aspectos técnicos, administrativos y pedagógicos, y que es el propósito de la Junta de Gobierno restablecer los principios del orden, disciplina y moralidad en los establecimientos educacionales ${ }^{36}$ se acordó reorganizar el sistema de enseñanza normal.

\footnotetext{
${ }^{33}$ Decreto Ley Número 128, 1974, pp. 90-91).

${ }^{34}$ En marzo de 1974 el Almirante José Toribio Merino señaló antes la consulta: «iqué motivaciones principales influyeron en Ud. para la decisión del once de septiembre? Muchas que se fueron escalonando a lo largo del tiempo. Sin embargo yo señalaría como primer indicio muy importante el informe que recibimos inmediatamente después de las elecciones parlamentarias últimas y cuyos resultados las Fuerzas Armadas entregaron a Allende sin que éste los difundiera. Nosotros, eso sí, guardamos las evidencias probatorias de que el sistema electoral estaba viciado», Revista Qué Pasa, (152), 22/03/1974, p. 9.

${ }^{35}$ Decreto Ley Número 130,1974, p. 94.

${ }^{36}$ Decreto Ley Número 179, 1974, p. 245.
} 
Para la realización de tan ambicioso proyecto se creó una Comisión Coordinadora Central. Esta Comisión estaba conformada por un Delegado de la Junta de Gobierno, el Jefe de Departamento de Enseñanza Normal, el Director del Centro de Perfeccionamiento, Experimentación e Investigaciones Pedagógicas y dos expertos en enseñanza normal. Éstos últimos fueron designados por el Ministro de Educación, así como por el Delegado de la Junta Militar. ${ }^{37}$

A comienzos de 1974 y siguiendo su política de control social, se determinó extender el Estado de sitio a todo el país; pero sin duda, y en esa misma línea de disciplinamiento y represión contra la población, el Decreto Ley 521, publicado en el Diario Oficial número 28.879 del 18 de junio de 1974, se constituyó en uno de los más significativos y trascendentes del primer año de la dictadura. Se trató de la creación de la Dirección de Inteligencia Nacional (DINA). El objetivo era crear un «organismo especializado que le proporcione en forma sistemática y debidamente procesada la información que requiera para adecuar sus resoluciones en el campo de la Seguridad y Desarrollo Nacional». Como una forma de facilitar dicho trabajo, la Junta Militar entregó todas las herramientas institucionales que la DINA requirió para su buen funcionamiento. Entre ellas presupuesto, personal (específico) de las Fuerzas Armadas y documentación o información que estuviera en posesión de algunos de los servicios del Estado, municipalidades, personas jurídicas creadas por ley o de sus empresas. ${ }^{38}$

Finalmente, se prohibió el ingreso al país a todas aquellas personas chilenas o extranjeras que «desde el exterior deshonren, difamen o desprestigien vilmente al país, a su Gobierno y a su pueblo, está atentando gravemente contra los intereses esenciales del Estado y, en el caso de los chilenos, renegando de su Patria». ${ }^{39}$

\section{Comentarios finales}

Una de las principales características y consecuencias que tuvo el golpe de Estado de 1973 en Chile fue la rápida implementación y puesta en práctica por parte de la Junta Militar de determinadas modalidades y

\footnotetext{
${ }^{37}$ Decreto Ley Número 179, 1974, pp. 246-247.

${ }^{38}$ Decreto Ley Número 521, 1974, pp. 78 a 81.

${ }^{39}$ Decreto Ley Número 604, 1975, p. 27.
} 
diseños de represión contra la población. En aquel nudo crítico de la historia reciente de Chile comenzaron a aplicarse los bandos militares y decretos ley, a la par que se ponía en marcha la creación de la Dirección de Inteligencia Nacional (DINA) como el principal dispositivo del terror y las Actas de la Honorable Junta de Gobierno. Todas estas disposiciones o dispositivos fueron estructurando un entramado normativo y discursivo a través del cual se expresó la violencia política e institucional del régimen liderado por Augusto Pinochet, no sólo al momento de la intervención militar, es decir, aquel martes 11 de septiembre y los días posteriores, sino durante los diecisiete años en los cuales se mantuvieron las Fuerzas Armadas en el gobierno. Como lo ha señalado la profusa producción que ha trabajado el régimen de Pinochet, la violencia, en el amplio sentido del término, fue la principal características de la dictadura, uno de sus sellos y parte fundante de su intervención y actuación en el tiempo.

Desencadenada la irrupción castrense, los bandos militares cumplieron aquella función represiva, dando el sustento jurídico para emprender las acciones de violencia contra la población. Posteriormente fueron los decretos ley los que pasaron a desempeñar aquel objetivo punitivo. Para los militares chilenos, también para un importante sector de la población y de civiles que respaldaban las acciones de disciplinamiento y control social, el país vivenció un período de «guerra interna», que se prolongó con diversos matices e intensidades durante los diecisiete años de dictadura. El objetivo inmediato de las Fuerzas Armadas fue demostrar a través de acciones concretas y directas que se estaba en guerra contra un enemigo interno que se había infiltrado en el país, subvirtiendo el orden institucional; de ahí entonces el objetivo de eliminar del territorio nacional todo aquello que significara un potencial peligro para la seguridad y unidad nacional.

Ante una institucionalidad quebrantada (en opinión de los militares), la Junta Militar instituyó sus propias normas y pautas de acción. Todas ellas funcionales a su objetivo inmediato de ejercer un rápido y violento control del poder público. La legitimidad del golpe de Estado de 1973 y la concerniente represión, vía una determinada legalidad, léase bandos militares y decretos ley se constituyeron en aquellos años en la expresión más visible de un poder militar disciplinario que terminó por instituir la violencia política como práctica institucional de una de las dictaduras más violentas y duraderas de la historia reciente de América Latina. 


\section{Referencias bibliográficas}

Aróstegui, J. (1996). La especificación de lo genérico: la violencia política en la perspectiva histórica. Sistema: revista de ciencias sociales, (132-133), 9-39.

Barros, R. (2005). La junta militar. Pinochet y la Constitución de 1980. Santiago, Chile: Sudamericana.

Cortina, A. (1996). Ética y violencia política. Sistema: revista de ciencias sociales, (132-133), 57-71.

Dorat, C. y Weibel, M. (2012). Asociación ilicita. Los archivos secretos de la dictadura. Santiago, Chile: CEIBO.

Escalante, J. (2013). Los crímenes que estremecieron a Chile. Las memorias de La Nación para no olvidar. Santiago, Chile: CEIBO.

Garcés, M. (2005). Para una historia de los DD.HH en Chile. Santiago, Chile: Lom.

Garreton, M. (1998). Por la fuerza sin la razón. Análisis y textos de los bandos de la dictadura militar. Santiago, Chile: Lom.

González, E. (2002). La violencia en la politica. Perspectivas teóricas sobre el empleo deliberado de la fuerza en los conflictos de poder. Madrid, España: Consejo Superior de Investigaciones Científicas.

Monsálvez, D. y Aravena, Y. (2018). Interpretaciones historiográficas sobre la violencia política en Chile. Folia Histórica del Nordeste, 8399.

Peñaloza, C. (2015). El camino de la memoria. De la represión a la justicia en Chile, 1973-2013. Santiago, Chile: Cuarto Propio.

Pizarro, C. y Santos-Herceg, J. (2016). Revisitar la catástrofe. Prisión politica en el Chile dictatorial. Santiago, Chile: Pehuén.

Rebolledo, J. (2012). La danza de los cuervos. El destino final de los detenidos desaparecidos. Santiago, Chile: CEIBO.

Salazar, M. (2011). Las letras del horror. Tomo I. La DINA. Santiago, Chile: Lom.

Salazar, M. (2012). Las letras del horror. Tomo II. La CNI. Santiago, Chile: Lom.

Salazar, M., Ramírez, A. y Hertz, C. (2016). Operación exterminio. La represión contra los comunistas chilenos (1973-1976). Santiago, Chile: Lom. 
Turk, A. (1996). La violencia política desde una perspectiva criminológica, Sistema: revista de ciencias sociales, (132-133), 41-55. 